\title{
O CONSTITUCIONALISMO NACIONAL E O DIREITO INTERNACIONAL*
}

\author{
MARK TUSHNET ${ }^{* *}$
}

\begin{abstract}
RESUMO: Este trabalho tem por objetivo o estudo de temários surgidos no Direito Internacional e cujo desenvolvimento de ideias vem surtindo efeitos para o Constitucionalismo interno. Enfatizam-se três circunstâncias que devem ser enfrentadas por estados-nações de modo que possam encontrar um senso comum em suas relações internacionais. As questões enfrentadas por este trabalho visam ao debate sobre a existência de divergências razoáveis no momento da aplicação dos direitos humanos e o problema de sua especificação. Além disso, este estudo identifica três fontes de tensão entre o direito internacional e o direito constitucional interno, concentrando-se na análise dessas tensões. Este trabalho enfrenta o debate sobre as implicações do direito internacional na interpretação constitucional nacional e a posição da nação (E.U.A.) no cenário internacional, especialmente a respeito da influência do direito internacional na interpretação constitucional levada a efeito pelos tribunais. Este trabalho se propõe a discutir o tema da globalização do direito constitucional e, mais especificamente, a internalização de normas não vinculantes de direito internacional nas constituições nacionais.
\end{abstract}

PALAVRAS-CHAVES: Direito Internacional; Direito Constitucional; Direitos Humanos; Interpretação Constitucional.

ABSTRACT: This paper seeks to examine the issues raised in International Law and its developments towards domestic Constitutionalism. Three circumstances are emphasized which nation states need to face in order to reach a common sense in their international relationship. The issues debated in this paper aim to discuss the existence of reasonable disagreements when human rights are enforced and the problem of specification. Further, the paper identifies three sources of tension between international law and domestic constitutional law and focus in an examination of these tensions. In addition, the paper examines the role of international law in domestic constitutional interpretation and the place of the nation (U.S.A.) in the international arena, especially in case of international law influence in domestic constitutional interpretation by courts.

Artigo recebido em 20.10.2010. Artigo aceito para publicação em 12.04.2011 mediante convite.

* Tradução do texto referente à palestra proferida no IX Seminário Internacional sobre Direitos Fundamentais: Os Direitos Fundamentais e o Direito Internacional (Porto Alegre, maio de 2010), brevemente modificada e atualizada pelo próprio autor. Tradutor: Sérgio Osborne Moreira Alves, advogado, Mestre em Direito pela Pontifícia Universidade Católica do Rio Grande do Sul, pesquisador do Grupo de Estudos e Pesquisas em Direitos Fundamentais (GEDEF) da PUCRS.

${ }^{* *}$ Professor da Faculdade de Direito da Universidade de Harvard, Estados Unidos. 
Therefore, it is proposed a debate about the globalization of constitutional law, and more specifically, the incorporation of non-binding international law in domestic constitutions.

KEYWORDS: International Law; Constitutional Law; Human Rights; Constitutional Interpretation.

Uma das evoluções mais perceptíveis no Direito Internacional Pós Segunda Guerra foi a transformaç̧ão de seu objeto, passando de uma ciência concentrada, quase que exclusivamente, no estudo das relações entre estados-nações soberanos para uma ciência cujo objeto também incluiria a preocupação com o estudo das relações dos estados-nações e os seus respectivos cidadãos. Este novo objeto de estudo, contudo, deverá levar em consideração, necessariamente, as diversas circunstâncias enfrentadas pelos estados-nações. Três destas circunstâncias serão enumeradas a seguir:

a) Estados-nações apresentam formas de Governo diversas. Instituiu-se uma compreensão segundo a qual o Direito Internacional estabelece uma espécie de direito à democracia ou auto-governo, uma concepção baseada, em parte, na influência exercida pelo princípio da auto-determinação dos povos no Direito Internacional. De qualquer sorte, tal influência não é forte, de modo que os estados-nações se mostram justificadamente recalcitrantes em reconhecer o direito de auto-determinação às minorias nacionais, por exemplo, ou a comunidades de imigrantes. No entanto, uma grande diversidade de formas de governo pode ser encontrada até mesmo entre membros do grupo de nações que possuem um regime democrático rudimentar. Estados-nações podem se organizar como democracias parlamentaristas ou através do sistema da separação de poderes, por exemplo. Um monarca constitucional pode desempenhar um importante papel em algumas democracias. Até mesmo um Estado moderadamente autoritário (a Singapura, por exemplo) não seria, provavelmente, reprovado pelo direito internacional em razão de falhas na concretização de direitos humanos fundamentais. Entretanto, junto ao amplo espectro de formas de governo com regimes democráticos rudimentares que podemos reconhecer, encontramos uma dificuldade correlata na tarefa de especificar o regime internacional de direitos humanos que conforte todas as variáveis toleradas.

b) Os estados-nações se diferenciam, de modo geral, em razão das circunstâncias sociais, econômicas e políticas que enfrentam. Podemos nos deparar com um determinado estado-nação que adote uma forma de governo democrático rudimentar, mas atenda aos padrões de proteção exigidos pelas normas internacionais de direitos humanos. Mesmo assim, estes estados-nações poderão ser forçados a enfrentar uma crise econômica ou uma revolução localizada que leve o governo a adotar medidas que, por si só, seriam medidas violadoras de direitos humanos em circunstâncias comuns. As normas internacionais de direitos humanos buscam confortar estas situações de duas formas: primeiro permitindo uma flexibilização das normas internacionais de direitos humanos, derrogando-as e construindo, na 
estrutura do sistema normativo daqueles direitos, razões especiais que permitam sua restrição. Em termos gerais, as condições para a derrogação estão estabelecidas em termos bem estritos, por exemplo, em caso de "ameaça à existência da nação", mas sua definição pode ser manejada com certa flexibilidade. O segundo método para lidar com as situações de incompatibilidades entre o direito internacional e as circunstâncias internas dos estados-nações é a criação de uma lista contendo os casos para os quais as restrições de direitos seriam permitidas. Tais listas são, de modo geral, extensas, contendo a maior parte dos casos em que se justificariam restrições a direitos pelo Estado. Neste sentido, as próprias listas não criariam restrições aos estados-nações além daquelas já existentes em seu âmbito interno. Na verdade, o trabalho efetivo é desempenhado pela construção do sentido de proporcionalidade, quando a avaliação internacional, que revele uma real necessidade de determinada restrição a direitos, entra em conflito com a avaliação levada a efeito no âmbito interno.

c) A terceira fonte de diversidade entre os estados-nações no que diz respeito a direitos humanos internacionais é, em nosso ponto de vista, a mais interessante de ser estudada. Direitos Constitucionais internos são positivados em termos relativamente abstratos, por exemplo, "liberdade de expressão". Estes direitos são aplicados em conflitos no mundo real e tais abstrações devem ser concretizadas para alcançar um conteúdo mais específico. Além disso, as pessoas nem sempre estão de acordo sobre os limites do âmbito de proteção de um direito positivado abstratamente na Constituição, discutindo acerca de sua aplicabilidade a determinadas situações quando problemas concretos estão em pauta. Denominamos este problema como "especificação". Acadêmicos que estudam o direito constitucional nacional entendem que várias das controvérsias sobre interpretação constitucional em âmbito nacional - controvérsias sobre a delimitação de direitos constitucionais - envolvem divergências razoáveis sobre o conteúdo do direito efetivamente garantido pela constituição. O exemplo mais comum é a regulação do discurso do ódio: alguns professores ensinam que a regulação do discurso do ódio é incompatível com as ideias mais básicas sobre a liberdade de expressão, enquanto outros professores debatem que tal regulação, além de não afrontar aquela liberdade, é necessária para proteger a própria liberdade de expressão e para proteger ideias de igualdade correlatas à liberdade. O ponto fulcral aqui é que ambas as posições são razoáveis. Mas o exemplo expõe outra dificuldade. Acadêmicos e demais pesquisadores tendem a assentir quanto à existência de divergências em âmbito abstrato, quando buscam delimitar o conteúdo de direitos constitucionais, mas dificilmente reconhecem que os argumentos contrários a suas próprias especificações possam ser, também, razoáveis.

Divergências razoáveis sobre o conteúdo dos direitos fundamentais se originam da reunião das duas dificuldades já mencionadas. Tomemos como um exemplo o direito de liberdade religiosa. As normas internacionais 
de direitos humanos protegem esta liberdade, porém, a doutrina especializada neste assunto reconhece que há uma interação complexa entre a regulação da liberdade religiosa e o exercício da mesma. Particularmente, algumas formas de regulação da liberdade religiosa - envolvendo participação forçada em práticas religiosas - parecem incompatíveis com a ideia de liberdade. O problema da especificação nos ensina que sempre haverá divergências razoáveis a respeito da possibilidade ou não de alguma atividade religiosa envolver a problemática "participação forçada" nesta atividade. Com enfeito, a utilização de recursos públicos arrecadados pela tributação para financiar atividades tipicamente religiosas nos Estados Unidos tem sido concebida como uma forma problemática de imposição, enquanto que o financiamento público de atividades estritamente religiosas em países que amplamente defendem a liberdade de religião vem sendo, de modo geral, aceito.

Gostaríamos de aprofundar um pouco mais o problema da especificação uma vez que o mesmo está diretamente relacionado com o direito internacional. As normas de direito internacional, de forma geral, não permitem reservas às disposições de tratados internacionais quando tais reservas sejam incompatíveis com os "objetivos e finalidades" dos mesmos e tanto a maioria das organizações de direitos humanos quanto pareceristas concordam que tal regra é aplicável a tratados que prevêem a proteção de direitos humanos. O Comitê de Direitos Humanos das Nações Unidas se pronunciou no sentido de proibir as reservas que efetivamente determinem que os estados-nações nada façam para modificar seu sistema normativo interno. Este pronunciamento pode ser interpretado restritivamente, de modo que se reconheça que tal posição se refira apenas a reservas extensas, ou seja, que venham a atingir muitos direitos humanos a ponto de fazer com que a adesão às normas internacionais se esvazie de sentido. Com uma interpretação um pouco mais ampla, no entanto, o pronunciamento passa a abordar questões sobre especificação. Vamos supor que o pronunciamento se refira a reservas em relação a determinados direitos nas quais se afirme que o tratado não está criando outras obrigações para os estados-nações além daquelas já garantidas no ordenamento constitucional interno. Por exemplo, os Estados Unidos declararam uma reserva à proibição de tratamento degradante e cruel contida no ICCPR alegando que o país estaria vinculado a esta proibição nos limites já previstos no ordenamento constitucional norte-americano. Vamos supor que o Conselho de Direitos Humanos das Nações Unidas considere algumas ações nas prisões americanas - a detenção em solitárias de condenados de alta periculosidade por um longo período de tempo - cruéis, desumanas e degradantes. Esta conclusão pode ser concebida como razoável. Da mesma forma, imaginemos que os tribunais norte-americanos decidam a favor das referidas condições e contra as alegações de violação do direito constitucional interno. Como devemos compreender esta divergência? Uma possibilidade é sustentar que a reserva declarada pelos Estados Unidos é incompatível com os objetivos e finalidades do tratado e que os Estados Unidos, portanto, estão 
violando as obrigações assumidas com a ratificação do tratado internacional. Entretanto, também poderia ser correto afirmar que a proibição de aplicação de penas degradantes e cruéis contida na Constituição norte-americana, segundo o conteúdo construído pelos tribunais norte-americanos, seja uma especificação razoável, em que pese diferente, daquela feita pela ICCPR sobre a proibição de tratamento degradante e cruel. Dessa forma, as reservas declaradas pelos Estados Unidos não seriam incompatíveis com as finalidades e objetivos da ICCPR.

Havíamos identificado três fontes de tensão entre as normas internacionais de direitos humanos e o direito constitucional interno. Passamos a analisar, agora, algumas das implicações que as referidas tensões refletem sobre os desígnios do direito internacional. Articulamos, em outra oportunidade, sobre um tema que denominamos a inevitável globalização do direito constitucional, tema para o qual pretendemos rebater algumas críticas lançadas a respeito da utilização do direito internacional em demandas judiciais constitucionais nos Estados Unidos.

Primeiramente, abordaremos o tema da globalização do direito constitucional. Iniciamos este estudo afirmando que o direito internacional situa-se em um processo de reconhecimento do chamado direito à democracia. Tal direito vem sendo concebido em decorrência do reconhecimento do direito internacional à auto-determinação. Esta teoria se baseia no fato de que o regime jurídico internacional não consegue identificar satisfatoriamente 0 significado de "auto-" que seja determinante em si mesmo a não ser que alguns processos democráticos razoáveis sejam adotados para identificar a vontade das pessoas a respeito de suas escolhas, isto é, se desejam ou não formar uma nação e, em caso afirmativo, em que termos desejam formá-la. Outrossim, os princípios para o reconhecimento de Estados que surgiram a partir da dissolução da antiga Yugoslávia e de outros eventos semelhantes no final do século $X X$ e início do século $X X I$ parecem exigir um novo requisito para que novos Estados tenham direito ao reconhecimento, pois além dos critérios tradicionais, tais como o controle efetivo sobre o território, passou-se a exigir também o respeito a determinados critérios de democracia.

O surgimento de um direito internacional à democracia é importante porque vem ocorrendo dentro dos domínios tradicionais do direito internacional que lida com relações de Estado para Estado. Contudo, seu significado é limitado, tendo em vista razões já expostas, ou seja, para satisfazer os requisitos mínimos de uma democracia se faz necessário que os acordos internacionais possuam um conteúdo amplo. O mesmo pode ser afirmado sobre os mais relevantes aspectos de normas internacionais sobre direitos humanos. Tais elementos vinculam-se ao empenho para garantir a satisfação de requisitos mínimos básicos - equidade, igualdade, e assim por diante em todos os lugares. As normas internacionais de direitos humanos têm por objetivo estabelecer um limite mínimo a ser respeitado pelos regimes constitucionais nacionais, fenômeno que se revela importante em um mundo 
onde a eficácia das garantias constitucionais nacionais de muitos estadosnações deixa muito a desejar, pois garantem menos do que aquele mínimo razoável almejado.

(Seria interessante tecermos alguns breves comentários sobre 0 denominado ceticismo realista a respeito do sistema internacional de direitos humanos. Tal ceticismo se baseia no fato de que muitos regimes repressivos comprometem-se verbalmente a cumprir com as obrigações impostas em nível internacional pelos direitos humanos, porém agem de outra forma na prática, descumprindo-as, bem como no fato de que muitos estados-nações que buscam respeitar e levar tais tratados mais a sério o fazem porque acreditam que os direitos e garantias previstos internamente são muito mais amplos do que os direitos e garantias previstos nos tratados. Dessa forma, seguindo o raciocínio, o regime internacional de direitos humanos seria inócuo - aquelas pessoas que mais necessitariam de sua proteção estariam vivendo sob governos que ignoram este regime na prática, enquanto que os cidadãos de estados-nações que respeitem tal regime nada têm a ganhar além daquilo que já possuem em seus sistemas internos de proteção jurídica. A crítica realista possui um fundo de razão, mas, de modo geral, há um exagero em seu postulado. Existem determinados casos em que o regime internacional de direitos humanos pode trazer um impacto real, sendo utilizado como uma ferramenta com determinados efeitos práticos pela sociedade civil e pelos operadores do direito que são, até certo ponto, talvez até modestamente, autônomos em face do regime interno. Acreditamos que esta versão mais moderada do pensamento realista encontra defensores de peso na comunidade acadêmica).

Um piso mundial de direitos humanos representa alguns avanços, em que pese tímidos, pois tal piso pode ser ínfimo. O fenômeno que denominamos de globalização do direito constitucional implica na ampliação deste piso, ou melhor, deixando de lado metáforas, significa irradiar garantias significativamente mais amplas do que aquelas previstas como um mínimo no atual sistema normativo internacional de direitos humanos. De que forma tais garantias podem ser propaladas? Seguindo a lição de outros acadêmicos, sugerimos mecanismos tanto "de cima para baixo" quanto "de baixo para cima"1. Anne Marie Slaughter destacou o mais importante mecanismo "de cima para baixo" - a construção de redes mundiais (e regionais) de juízes constitucionais e, acrescentaríamos, a criação de organismos da sociedade civil para atuarem conjuntamente às referidas redes, para estimular o intercâmbio de ideias e promover o amparo mútuo contra decisões internas de gestores e órgãos de decisão que optem por não observar os altos padrões de proteção das garantias constitucionais. Devemos levar em consideração que os efeitos das referidas redes são contingentes e cremos que seria possível vivenciarmos, ainda, o surgimento de contra-redes, nas

\footnotetext{
${ }^{1}$ A expressão no original é "top-down" e "bottom-up".
} 
quais os participantes construiriam uma coalizão de ideias contra a ampliação das garantias constitucionais.

Desenvolvemos um trabalho sobre os mecanismos "de baixo para cima" ao lado das pesquisas desenvolvidas pelo professor David Law, reconhecendo que um dos mecanismos mais importantes encontrados foi o mercado neo-liberal no qual o capital existente e um alto nível de capital humano os denominados "trabalhadores intelectuais" - migravam de uma forma relativamente livre atravessando fronteiras. Os detentores de capital efetivo se interessavam por garantias contra a expropriação, que podem ser alcançadas pelas garantias constitucionais relacionadas ao direito de propriedade. (Não abordaremos algumas exceções importantes para este argumento, especialmente no sentido de que o sistema normativo constitucional possa promover a garantia até determinado limite através da edificação de um Poder Judiciário independente). Contudo, os investimentos também exigem estabilidade social e política e a história nos traz evidências empíricas de que tal estabilidade acaba sendo melhor sedimentada, a longo prazo, em sistemas onde os direitos fundamentais sejam garantidos e onde também seja possível vislumbrar traços democráticos em face de nações significativamente mais autoritárias. (Novamente, preferimos omitir algumas exceções importantes). Desta forma, até mesmo os investidores têm algum interesse em fazer pressão para o reconhecimento de direitos humanos pelos regimes constitucionais internos, alguns direitos de forma mais substancial do que o mínimo garantido pelo regime internacional de direitos humanos.

Os interesses daquele grupo que possui os mais altos níveis de capital humano seriam ainda mais importantes. Estas pessoas, tipicamente, exigem uma proteção substancial para suas liberdades individuais. Alguns exigem o mesmo nível de proteção que possuem em seu país de origem; outros gostariam de criticar o governo das nações onde estejam residindo sem temer retaliações ou a expulsão. Além disso, parece haver dificuldades em satisfazer as exigências destes trabalhadores de alto nível sem promover as proteções que eles buscam e, da mesma forma, estendê-las para toda a população. Novamente omitimos, aqui, algumas exceções importantes, mas não podemos deixar de mencionar duas em particular. Os regimes jurídicos nacionais não devem se sentir pressionados por trabalhadores intelectuais (que esperam receber altos níveis de proteção), caso tais regimes não necessitem traze-los para trabalhar em seu território, desde que seja possível prepará-los nacionalmente. Além disso, sendo possível a segregação destes trabalhadores intelectuais, separando-os do resto da sociedade, que acreditamos ser um fato viável se as referidas pessoas prosperassem no ambiente da nação, eles teriam direito a proteção constitucional para além de um patamar mínimo enquanto que os demais membros da sociedade permaneceriam com uma proteção mínima ou mesmo inferior a este nível.

Dessa forma, tanto os interesses de investidores estrangeiros quanto os interesses daqueles trabalhadores intelectuais não nacionais impõem a 
adoção das garantias conferidas pelos direitos humanos em outras nações para além do mínimo já garantido pelas normas internacionais de direitos humanos, uma vez que a necessidade dos investidores para atuar em um ambiente estável somente seria satisfeita se estes direitos fossem garantidos em nível superior aquele mínimo e porque os trabalhadores intelectuais demandam, precisamente, garantias para além do mínimo. Tendo apresentado este argumento em vários lugares, especialmente nos Estados Unidos, podemos afirmar que o mesmo tem sido recepcionado com alto grau de descrença, sendo que gostaríamos de abordar um aspecto específico deste ceticismo que toma como ponto de partida uma controvérsia recentemente levantada nos Estados Unidos a respeito da influência que o direito internacional exerce sobre a interpretação constitucional interna.

Em razão da repercussão causada pela controvérsia, pelo menos nos Estados Unidos, seria importante enfatizar que as primeiras experiências, nas quais o direito internacional é utilizado pela Suprema Corte Norte-americana na interpretação constitucional, tem sido bem modestas. Além disso, a consequência mais importante destas experiências é a reafirmação, em termos mais contundentes, de que a posição adotada pelos Estados Unidos em face da aplicação do direito internacional é uma posição, utilizando-se o vocabulário típico da área, muito mais dualista do que monista. Analisemos, primeiramente, este último argumento. Tendo rejeitado o entendimento segundo o qual o estatuto da Corte Internacional de Justiça implica que suas decisões sejam tão vinculantes quanto o direito norte-americano, independentemente de qualquer ato por parte do Legislativo, a Suprema Corte decidiu que tratados internacionais considerados auto-executáveis - tratados que produzem efeitos internos sem qualquer atuação do Legislativo nacional e, assim, se aproximam da tradição monista - segundo a visão norte-americana, devem estabelecer tal auto-executoriedade de forma expressa e em termos razoavelmente claros. Criando-se, assim, uma presunção contrária ao reconhecimento da auto-executoriedade - logo, uma presunção pelo dualismo - a Suprema Corte passou a aplicar tal presunção e, de forma razoável, tem decidido que os julgamentos da Corte Internacional de Justiça não são automaticamente vinculantes. (Devemos acrescentar que tal posição se justificaria mesmo sem uma presunção pelo dualismo).

Estamos certos de que a posição adotada pela Suprema Corte a respeito desta questão em particular resultou do contexto no qual a mesma foi debatida - a aplicação da pena de morte nos Estados Unidos, a oposição da comunidade internacional sobre o tema, bem como a maneira irrefletida com que a Corte Internacional de Justiça lidou com o tema dos remédios jurídicos internos para resolver o problema do desrespeito a obrigações internacionais. Mesmo assim, colocando-se tais questões de lado, verifica-se que o dualismo é um tema presente no discurso sobre o direito internacional e, além disso, a aparente presunção pelo dualismo adotada pela Suprema Corte - que pode ser afastada em contextos menos controvertidos - não significa, 
por si mesma, uma oposição ao direito internacional.

Os "usos" controversos do direito internacional tem sido raros e, novamente, seu campo fértil está, principalmente, nos casos em que se debate a pena de morte, havendo algumas referências breves, também, em casos envolvendo ações afirmativas, num dos quais a juíza Ruth Bader Ginsburg relatou que a fixação de um prazo-limite para as ações afirmativas era uma prática consistente com o método adotado no direito internacional. Nos casos envolvendo pena de morte para criminosos que cometeram os crimes antes de atingir a maioridade, ou para aqueles casos em que o perpetrador é retardado ou doente mental, as decisões por maioria da Suprema Corte tem levado em consideração as determinações encontradas em tratados internacionais. Os tratados não são imediatamente vinculantes para os Estados Unidos, seja porque este país não os ratificou, seja porque o país editou algumas modificações no texto do tratado para ratifica-lo. A maioria da Suprema Corte não baseou seu julgamento diretamente nestes tratados. Ao invés disto, a Suprema Corte enfrentou um debate constitucional com base em métodos comuns de interpretação constitucional e, ao final, chegou ao entendimento de que o julgamento segundo aquele método interpretativo adotado era compatível e se identificava com os argumentos defendidos pelos tratados. (A Suprema Corte também traz referências desta confirmação na prática jurisdicional de outros países, onde se invoca o direito comparado ao invés do direito internacional, em que pese os debates travados no âmbito dos Estados Unidos tenham obscurecido ambas as categorias).

Estas decisões abriram espaço para discussões intensas nos Estados Unidos, porém é importante que não se dê uma importância maior a tais controvérsias do que elas realmente merecem. Grande parte das discussões se revela apenas como um reflexo de outras questões sobre a interpretação constitucional. Muitos daqueles que criticam a posição da Suprema Corte, por exemplo, acreditam que o único fundamento apropriado para a interpretação constitucional deveria estar sedimentado na compreensão da Constituição à época de sua promulgação. Defendem, portanto, que fazer referências ao direito internacional representa um equívoco - mas um equívoco igual a qualquer outra compreensão da constituição que não estivesse conforme sua "concepção original" à época da promulgação. Outros se opõem às decisões da Suprema Corte a respeito da pena de morte tecendo argumentos pertinentes ao mérito das mesmas, entendendo errôneas as decisões de cada um dos juízes em sua totalidade e não simplesmente quanto ao aspecto da referência ao direito internacional. Surpreendentemente, juristas liberais mais proeminentes, acadêmicos e até mesmo políticos não aderiram a tais críticas, ou as rejeitaram expressamente entendendo-as como infundadas.

Mesmo infundada, entretanto, a controvérsia merece alguma atenção porque, no final, poderá revelar importantes elementos em razão das interações mais amplas entre o direito internacional e o constitucionalismo interno. Destacaremos duas destas interações, a primeira baseada na função 
desempenhada por organizações não-governamentais transnacionais em ações judiciais e, em segundo lugar, a forte influência que os Estados Unidos exercem no cenário internacional, pois os dois exemplos trazem implicações para além da controvérsia específica encontrada nos Estados Unidos.

Primeiramente, em cada um dos casos citados as organizações não-governamentais que denominamos, sem muita exatidão, de transnacionais protocolaram relatórios a título de amicus curiae. Estas organizações alegaram que as práticas em questão representavam violações do direito internacional costumeiro: a prática estatal relevante, corroborada tanto pelos tratados internacionais quanto por outras fontes de direito internacional, tornou-se suficientemente difundida a ponto de criar um direito internacional costumeiro. Em nosso ponto de vista, estes argumentos são claramente exagerados, ignorando o papel desempenhado pelos Estados Unidos como um opositor persistente de matérias que precisamente eram o objeto de julgamento na Suprema Corte e poderiam prosperar apenas se as normas fossem inaceitavelmente caracterizadas como normas jus cogens. Poderíamos imaginar que ninguém se importaria com as afirmações exageradas sobre o conteúdo do direito internacional costumeiro. Tais afirmações poderiam ser contestadas, como ocorre com qualquer tipo de alegação jurídica, por argumentos contrários sobre o mérito ao invés de simplesmente rejeitar a ideia de invocar o direito internacional em litígios a respeito do direito constitucional interno. Mesmo assim, o fenômeno da participação das organizações nãogovernamentais em ações judiciais que discutem problemas constitucionais internos é o ponto central da questão. O envolvimento destas instituições revela-se como outro mecanismo de globalização do direito constitucional uma vez que elas tomam por base o direito internacional e o direito constitucional de outras nações para embasar seus argumentos.

No entanto, nos Estados Unidos e provavelmente em outros lugares também, a presença de organizações não-governamentais transnacionais pode dar espaço a algumas tensões nos tribunais nacionais. Neste sentido, ao contestar alegações protocoladas por organizações não-governamentais, ocorreria uma transferência de parte da soberania para outro lugar. Isto quer dizer que ao respondermos os argumentos lançados por aquelas organizações, mesmo que seja apenas para rejeitá-los, estaríamos abrindo espaço para que os tribunais os aceitassem em outros casos e, agindo desta maneira, os tribunais seriam direcionados a buscar no direito internacional, ou estrangeiro, os fundamentos normativos a serem aplicados no sistema constitucional interno. As normas de direito internacional imediatamente vinculantes produzem, evidentemente, o mesmo efeito sobre a soberania, mas o problema que aqui debatemos é a utilização do direito internacional em um determinado contexto - interpretação constitucional - onde tal direito não é diretamente vinculante.

Assim, como eu havia indicado, o segundo ponto que pretendo desenvolver se relaciona à utilização do direito internacional na interpretação da constituição nacional como fonte de tensões que versam sobre o lugar 
da nação na arena internacional. Nossa análise se concentrará, novamente, no caso dos Estados Unidos, que historicamente possui duas correntes de pensamento sobre o lugar que este país ocupa no mundo. A primeira diz respeito à singularidade do caso americano, segundo a qual os valores adotados pela nação são incomparáveis e deveriam ser adotados em outros lugares - mas mesmo quando não adotados, deveriam ser considerados essenciais para o auto-conhecimento da nação. O segundo, claro, é o internacionalismo cosmopolita que em parte representa o empenho para exportar os valores nacionais pelo mundo afora, mas, por outro lado, também representa uma abertura para valores considerados mais importantes no exterior do que nos Estados Unidos. Estas correntes de pensamento estiveram em tensão por boa parte da história dos Estados Unidos. Quando os Estados Unidos possuíam uma força militar enfraquecida, por exemplo, o internacionalismo cosmopolita implicava na imposição de valores estrangeiros para o povo americano. Porém, em outras circunstâncias, ambas as correntes de pensamento se fortaleciam mutuamente. Quando os Estados Unidos estavam competindo pela liderança mundial com a União Soviética, por exemplo, a singularidade Americana, na sua versão de "exportação de valores", adaptou-se perfeitamente no internacionalismo cosmopolita, especialmente quando os Estados Unidos demonstravam-se receptivos a valores de outras nações para determinar suas políticas internas e internacionais. Algo provavelmente semelhante ocorreu durante um breve período no final do século $X X$ quando os Estados Unidos era a única superpotência mundial em termos militares e econômicos.

No entanto, a singularidade americana e o internacionalismo cosmopolita caminham inquietantemente juntos em períodos como o atual, no qual, segundo nossa opinião, os Estados Unidos são uma importante força internacional, mas não a única potência internacional. Caso o direito interno fosse influenciado pelo direito internacional, este fenômeno simplesmente ressaltaria que os Estados Unidos seriam apenas mais uma nação entre muitas outras e, especialmente, segundo nosso ponto de vista, não seria uma nação intrinsecamente mais importante do que as denominadas B.R.I.C. (Brasil, Rússia, Índia e China). A inquietação quanto à posição dos Estados Unidos na arena internacional é, conforme acreditamos, uma das razões mais importantes que justificariam as controvérsias em torno da questão sobre limites da utilização do direito internacional na interpretação constitucional nacional.

Apesar de não sermos especialistas no direito e na auto-compreensão de outras nações, não nos surpreenderia encontrar casos semelhantes, mas não iguais, que surgem em razão do debate acerca do papel do direito internacional na interpretação constitucional nacional. O exemplo mais elucidativo é, provavelmente, o da África do Sul, no qual a Constituição da era pós-apartheid determina que os tribunais interpretem a carta de direitos (bill of rights) levando em consideração o direito internacional. Este fato é uma demonstração razoavelmente clara da auto-compreensão daquela nação 
como uma liderança em direitos humanos internacionais, especialmente em razão da sua experiência com a era do Apartheid. Outras nações, tais como Singapura, argumentam que seus programas normativos nacionais são incomparáveis de forma que o direito internacional deve participar de forma mínima na construção daquele sistema normativo. (Alguém poderia sustentar uma postura de ceticismo em relação a esta afirmação sobre o direito nacional na Singapura, porém seus líderes, juízes dos Tribunais Superiores inclusive, a defendem). Assim, em que pese haver pressões para o reconhecimento da globalização do direito constitucional, incluindo a incorporação de postulados não vinculantes do direito internacional nas constituições nacionais, também há pressões em sentido contrário. Como estas pressões em tensão encontrarão o ponto de equilíbrio ainda é uma questão que está sem resposta, contudo, acreditamos que há razões estruturais - basicamente associadas com a globalização em suas outras formas - para cogitar que a globalização do direito constitucional é, de fato, inevitável, analisando-se a longo prazo. 